Lecture Notes in Civil Engineering

Paulo A. G. Piloto

João Paulo Rodrigues

Valdir Pignatta Silva Editors
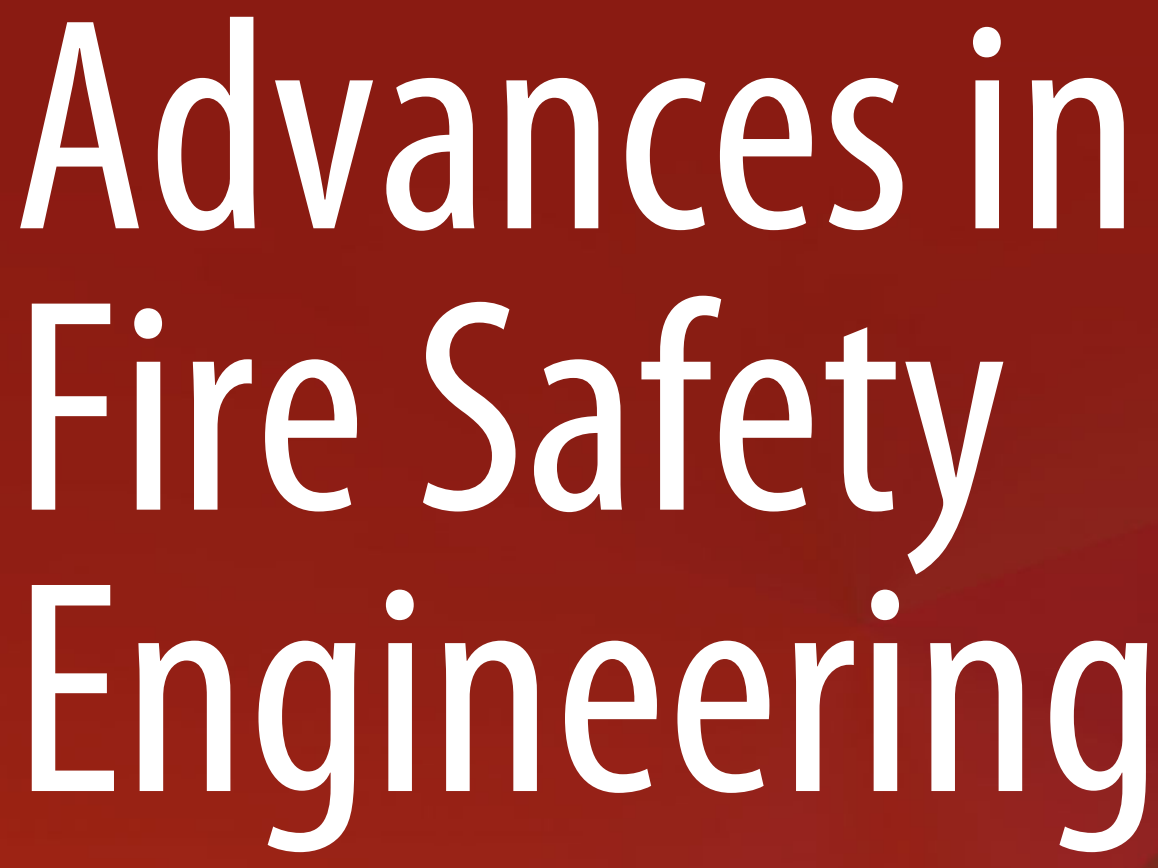

Selected Papers from the

5th Iberian-Latin-American Congress

on Fire Safety, CILASCI 5,

July 15-17, 2019, Porto, Portugal

Springer 


\section{Lecture Notes in Civil Engineering}

\section{Volume 1}

\section{Series Editors}

Marco di Prisco, Politecnico di Milano, Milano, Italy

Sheng-Hong Chen, School of Water Resources and Hydropower Engineering, Wuhan University, Wuhan, China

Ioannis Vayas, Institute of Steel Structures, National Technical University of Athens, Athens, Greece

Sanjay Kumar Shukla, School of Engineering, Edith Cowan University, Joondalup, WA, Australia

Anuj Sharma, Iowa State University, Ames, IA, USA

Nagesh Kumar, Department of Civil Engineering, Indian Institute of Science Bangalore, Bangalore, Karnataka, India

Chien Ming Wang, School of Civil Engineering, The University of Queensland, Brisbane, QLD, Australia 
Lecture Notes in Civil Engineering (LNCE) publishes the latest developments in Civil Engineering - quickly, informally and in top quality. Though original research reported in proceedings and post-proceedings represents the core of LNCE, edited volumes of exceptionally high quality and interest may also be considered for publication. Volumes published in LNCE embrace all aspects and subfields of, as well as new challenges in, Civil Engineering. Topics in the series include:

- Construction and Structural Mechanics

- Building Materials

- Concrete, Steel and Timber Structures

- Geotechnical Engineering

- Earthquake Engineering

- Coastal Engineering

- Ocean and Offshore Engineering; Ships and Floating Structures

- Hydraulics, Hydrology and Water Resources Engineering

- Environmental Engineering and Sustainability

- Structural Health and Monitoring

- Surveying and Geographical Information Systems

- Indoor Environments

- Transportation and Traffic

- Risk Analysis

- Safety and Security

To submit a proposal or request further information, please contact the appropriate Springer Editor:

- Mr. Pierpaolo Riva at pierpaolo.riva@springer.com (Europe and Americas);

- Ms. Swati Meherishi at swati.meherishi@springer.com (Asia - except China and Australia/NZ);

- Ms. Li Shen at li.shen@springer.com (China).

\section{Indexed by Scopus}

More information about this series at http://www.springer.com/series/15087 
Paulo A. G. Piloto • João Paulo Rodrigues ·

Valdir Pignatta Silva

Editors

\section{Advances in Fire Safety Engineering}

Selected Papers from the 5th

Iberian-Latin-American Congress on Fire

Safety, CILASCI 5, July 15-17, 2019,

Porto, Portugal

照 Springer 


\section{Editors}

Paulo A. G. Piloto

Instituto Politécnico de Bragança

Bragança, Portugal

Valdir Pignatta Silva

Universidade de São Paulo

São Paulo, Brazil

\author{
João Paulo Rodrigues \\ Universidade de Coimbra \\ Coimbra, Portugal
}

ISSN 2366-2557

ISSN 2366-2565 (electronic)

Lecture Notes in Civil Engineering

ISBN 978-3-030-36239-3

ISBN 978-3-030-36240-9 (eBook)

https://doi.org/10.1007/978-3-030-36240-9

\section{(C) Springer Nature Switzerland AG 2020}

This work is subject to copyright. All rights are reserved by the Publisher, whether the whole or part of the material is concerned, specifically the rights of translation, reprinting, reuse of illustrations, recitation, broadcasting, reproduction on microfilms or in any other physical way, and transmission or information storage and retrieval, electronic adaptation, computer software, or by similar or dissimilar methodology now known or hereafter developed.

The use of general descriptive names, registered names, trademarks, service marks, etc. in this publication does not imply, even in the absence of a specific statement, that such names are exempt from the relevant protective laws and regulations and therefore free for general use.

The publisher, the authors and the editors are safe to assume that the advice and information in this book are believed to be true and accurate at the date of publication. Neither the publisher nor the authors or the editors give a warranty, expressed or implied, with respect to the material contained herein or for any errors or omissions that may have been made. The publisher remains neutral with regard to jurisdictional claims in published maps and institutional affiliations.

This Springer imprint is published by the registered company Springer Nature Switzerland AG The registered company address is: Gewerbestrasse 11, 6330 Cham, Switzerland 


\section{Preface}

This book gathers selected contributions presented during the 5th Iberian-Latin-American Congress on Fire Safety (CILASCI), held in Porto, Portugal, from 15-17 July 2019. The CILASCI is held once every two years, with the aim of disseminating scientific and technical knowledge in the field of fire safety, attracting different players involved in this area of knowledge.

The 5th Iberian-Latin-American Congress on Fire Safety reflected the new developments achieved in a wide range of application areas. The papers included in this book were selected out of 78 manuscripts (full papers), and five invited lectures, written and presented during six parallel sessions from researchers around the world (Algeria, Australia, Belgium, Brazil, China, Czech Republic, France, Hong Kong, Italy, Mozambique, Portugal, Spain, UK and USA).

The selected papers were peer-reviewed during and after the congress, and this selection process has resulted in new, extended, revised and full original versions covering the experimental analysis of materials and structures, the computational modelling of structures and materials, the fire events in special buildings and spaces, the architectural issues and evacuation topics for fire safety in buildings.

Fire safety has been advancing fast as a result of research, development and innovation worldwide; the new research programmes, the support of new skilled professionals and the existence of advanced training programmes in Fire Science Technology are not only expected to increase the safety level of people, buildings and products, but are also going to produce a positive impact in the economy of each country and society.

The editors gratefully acknowledge the members of the scientific committee and the experts who carried out the reviews of the manuscripts. They are also grateful to the organizing committee from the Polytechnic Institute of Bragança (IPB), the 
Faculty of Engineering of the University of Porto (FEUP) and the School of Engineering (ISEP) from the Polytechnic Institute of Porto, and the support from the Luso-Brazilian Association for Fire Safety (ALBASCI) is also acknowledged.

Paulo A. G. Piloto João Paulo Rodrigues Valdir Pignatta Silva 


\section{Contents}

Model Error for Calculating the Structural Reliability of Dowel Connections in Fire Situations . . . . . . . . . . . . . 1 Auro Cândido Marcolan Júnior and Poliana Dias de Moraes

Three-Dimensional Numerical Analysis on the Fire Behaviour

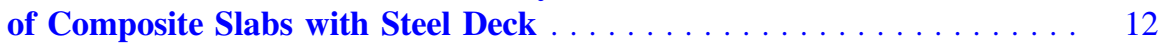
Paulo A. G. Piloto, Carlos Balsa, Fernando F. Ribeiro, and Ronaldo Rigobello

Durability of Reaction to Fire Performance of Wood Based Panels Through Accelerated Aging Cycles . . . . . . . . . . . . . . 31 Luís Mesquita, Lucas Ferle, and Gerson Santos

Modelling Real Fire by FDS and 2-Zone Model for Structural

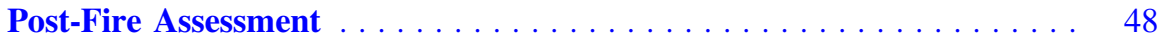

Tom Molkens and Barbara Rossi

Buckling Resistance of Partially Encased Columns Embedded

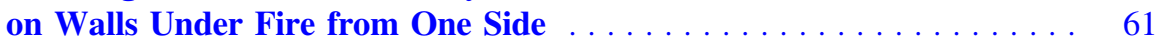

Paulo A. G. Piloto, Nathália Gonçales, Ronaldo Rigobello, Mário Vaz, Rui M. Guedes, and João S. Baptista

Numerical Analysis of Cellular Steel Beams Failure Modes in Fire Conditions

Jaqueline Silva, Paola Dalcanal, and Luís Mesquita

Wood Connections Under Fire Conditions Protected with Gypsum Plasterboard Types $\mathbf{A}$ and $\mathbf{F} \ldots \ldots \ldots \ldots \ldots \ldots \ldots \ldots \ldots$

Elza M. M. Fonseca, Pedro A. S. Leite, and Lino Silva

Emergency Exits: Analysis and Reflection Based on a Modelling and Standardization Study .

Edna Moura Pinto and Mariana Lima Oliveira Montenegro 
Performance of Plaster Walls Exposed to High Temperatures . . . . . . . 121

Roberta Tabaczenski de Sá, Cristovão J. D. Feitósa, José J. Bezerra,

Tiago A. C. Pires, José J. Rêgo Silva, and Cleandro O. S. Alencar

Author Index . . . . . . . . . . . . . . . . . . . . . . . . . . . . . 131 


\title{
Durability of Reaction to Fire Performance of Wood Based Panels Through Accelerated Aging Cycles
}

\author{
Luís Mesquita $^{1(\bowtie)}$, Lucas Ferle ${ }^{2}$, and Gerson Santos ${ }^{3}$ \\ ${ }^{1}$ Institute for Sustainability and Innovation in Structural Engineering (ISISE), \\ Instituto Politécnico de Bragança, Campus de Santa Apolónia, \\ 5301-857 Bragança, Portugal \\ lmesquita@ipb.pt \\ 2 Instituto Politécnico de Bragança, Campus de Santa Apolónia, \\ 5301-857 Bragança, Portugal \\ lucascferle@gmail.com \\ ${ }^{3}$ Departamento de Engenharia Mecânica, Universidade Tecnológica Federal do \\ Paraná (UTFPR), Curitiba, Brazil \\ gsantos@utfpr.edu.br
}

\begin{abstract}
Wood and wood based products application in the construction is growing due to the increasing trend of sustainable development. Because of the EU policy about constructions, each time requiring improved products against fire hazard, there is a need of developing fireproof products to wood and wood based panels and know their life time behavior.

To evaluate the performance and durability of fire retarded wood based panels, concerning mechanical and reaction to fire behavior, an experimental study is done considering the long term behavior of wood based panels with and without fire retardant products after being submitted to accelerated aging and compared to non-aged wood based panels. Fire reaction was carried out through cone calorimeter tests to evaluate if the fire reaction properties were maintained or altered after exposure to environmental conditions.

In terms of mechanical properties, MDF and PB panels had significant losses in MOR and MOE values after being submitted to aging. This behavior is not so clear for OSB panels. Reduction in mechanical properties are smaller for MDF panels with flame retardant when compared to MDF without flame retardant whereas PB without flame retardant showed small losses compared to PB with flame retardant. MDF panels without flame retardant presented a decrease in the fire reaction properties, releasing more heat after aging, whereas in the $\mathrm{PB}$ and OSB without flame retardant properties were maintained. MDF and PB fire retardant panels reaction to fire behavior before and after aging allows to maintain them in class B of fire reaction.
\end{abstract}

Keywords: Durability $\cdot$ Accelerated aging $\cdot$ Wood based panels $\cdot$ Fire retardants $\cdot$ Fire reaction 


\section{Introduction}

Wood is being used by humans since the early civilizations, and was one of the most important materials used the building construction. In recent years, due to ecological and environmental policies and restrictions in Europe, wood, wood products and wood structural elements have being positioned as a green raw material, Ecologically Sustainable and renewable material with a positive impact in the buildings carbon dioxide emissions in comparison to other construction materials, such as steel, concrete and bricks. The EUs driving policies for a competitive economy with low carbon emissions, [1], boost its architectural and engineering application in the building industry, but actually subjected to an higher demand in terms of its life cycle performance basic requirements, such as the sustainable use of natural resources, mechanical resistance and stability and Safety in case of fire, among others, [2].

The disseminated use of wood and wood products in the building construction have led to a need of wood based product development (Engineered wood products), namely wood-based panels, such as particle board (PB), medium density fibreboard (MDF), plywood, hardboards and wood flooring, [3], and wood structural members from large wood panel construction using cross-laminated timber (CLT), and others [4].

Being a hygroscopic material, wood thermal and mechanical properties, and aesthetic appearance, are affected by its surrounding environment, regarding temperature, humidity and direct or indirect solar radiation in outdoor and indoor appliances. Furthermore, when the moisture content is above $20 \%$, wood is susceptible to attack by fungi and bacteria. Structural wood products when exposed to excessive moisture variations can lead to swelling or shrinkage causing warping and cracking of the element reducing its mechanical properties, stability and durability. Additionally, wood structural elements with superficial cracks will have their reaction and resistance to fire reduced as the fire will propagate through them leading to a faster cross section charring rate and heat release rate (HRR). For these reasons different wood treatment methods, physical or chemical treatments, are used to increase wood stability and durability, and improving the resistance to biological degradation, fire resistance, UV resistance and mechanical properties, [4, 5]. Currently applied superficial chemical treatments include coating moisture-, bio-, fire- or UV-resistant agents on the surface of wood.

Wood is considered a flammable material, and although it has an intrinsic/natural fire protection, charring to decrease the heating rate, from the European standard fire classification of construction products and building elements, EN13501-1 [6], untreated wood is usually classified as being of class D, with lower density products in class E. This classification system considers the reaction to fire performance, smoke production and flaming droplets/particles. When fire retardant treatments are applied wood products can reach $\mathrm{C}$ and $\mathrm{B}$ class levels. Table 1 shows how the classification of construction products is made based on fire reaction levels [7]. 
Table 1. Classification of the reaction to fire of wood products.

\begin{tabular}{l|l|l|l}
\hline $\begin{array}{l}\text { Euro } \\
\text { class }\end{array}$ & $\begin{array}{l}\text { Smoke } \\
\text { class }\end{array}$ & $\begin{array}{l}\text { Burning droplets } \\
\text { class }\end{array}$ & Typical products \\
\hline A1 & - & - & Stone, concrete \\
\hline A2 & s1 s2, or s3 & d0 d1 or d2 & Gypsum boards (thin paper), mineral wool \\
\hline B & s1 s2, or s3 & d0 d1 or d2 & $\begin{array}{l}\text { Gypsum boards (thick paper), fire retardant } \\
\text { wood products }\end{array}$ \\
\hline C & s1 s2, or s3 & d0 d1 or d2 & Coverings on gypsum boards \\
\hline D & s1 s2, or s3 & d0 d1 or d2 & Wood, wood-based panels \\
\hline E & - & - or d2 & Some synthetic polymers \\
\hline F & - & - & No tested or incapable of achieving Class E \\
\hline
\end{tabular}

Additionally, when wood products are protected with non-fire retardant coatings their ignition properties and flame spread are influenced by the coating chemical composition and film thickness, [8, 9]. Wood treatment with fire retardant coatings (FRC) or intumescent fire retardant coatings (IFRC), [10], can overcome these weaknesses when wood products are exposed to fire and, for wood structural elements, assure the required fire resistance and load bearing capacity to be used in the building construction, meeting the requirements of the Eurocode 5, [11], based on the National fire safety codes requirements.

Table 2. Requirements for DRF Classes of fire-retardant wood products in interior and exterior end use applications, [12].

\begin{tabular}{|c|c|c|c|c|}
\hline \multicolumn{2}{|c|}{ DRF class } & \multirow{2}{*}{$\begin{array}{l}\text { Existing fire } \\
\text { requirements } \\
\text { Reaction to } \\
\text { fire class, } \\
\text { initial }\end{array}$} & \multicolumn{2}{|c|}{$\begin{array}{l}\text { Additional performance requirements at different end } \\
\text { use of fire retardant wood-based products }\end{array}$} \\
\hline & Intended use & & Hygroscopic properties & $\begin{array}{l}\text { Reaction to fire } \\
\text { performance after weather } \\
\text { exposure }\end{array}$ \\
\hline INT1 & $\begin{array}{l}\text { Interior dry } \\
\text { applications }\end{array}$ & $\begin{array}{l}\text { Relevant fire } \\
\text { class }\end{array}$ & - & - \\
\hline INT2 & $\begin{array}{l}\text { Interior } \\
\text { humid } \\
\text { applications }\end{array}$ & $\begin{array}{l}\text { Relevant fire } \\
\text { class }\end{array}$ & $\begin{array}{l}\text { - Moisture content }<28 \% \\
\text { - No exudation of liquid } \\
\text { - Minimum visible salt } \\
\text { with no increase at surface }\end{array}$ & - \\
\hline EXT & $\begin{array}{l}\text { Exterior } \\
\text { applications }\end{array}$ & $\begin{array}{l}\text { Relevant fire } \\
\text { class }\end{array}$ & $\begin{array}{l}\text { - Moisture content }<28 \% \\
\text { - No exudation of liquid } \\
\text { - Minimum visible salt } \\
\text { with no increase at surface }\end{array}$ & $\begin{array}{l}\text { Maintained reaction to fire } \\
\text { performance -after } \\
\text { - Accelerated weathering or } \\
\text { - Natural weathering } \\
\text { Application of specified } \\
\text { maintenance may be } \\
\text { included }\end{array}$ \\
\hline
\end{tabular}


Fire retardants applied in the products surface or by pressure impregnation may considerably improve the fire properties of wood and wood products, but the long term durability of this protection is not fully known. It is expected that, mainly in exterior applications but also in interior humid conditions, the fire retardant efficiency may reduce due to its hygroscopicity, $[13,14]$ and water solubility of the chemicals used.

The recent standard EN16755, [12], specifies a new classification testing for Durability of Reaction to Fire performance (DRF) based mainly on the Nordtest standard NT Fire 054 [15], which was based on earlier ASTM standards, namely the D2898-94. This classification is based on the intended use, considering interior dry and humid applications and exterior applications, as shown in Table 2. For exterior applications, the reaction to fire performance after weather exposure can be classified using natural or accelerated weathering.

To evaluate the performance and durability of fire treated wood based panels on the thermal and mechanical properties, including reaction to fire, a study is being done considering the long term behavior of wood products with and without fire retardant products after being submitted to accelerated aging and compared to non-aged wood products.

A set of experimental tests are performed towards the mechanical characterization and fire reaction of different wood based panels with and without fire retardant products, according to the EN 310 standard [16] to determine bending strength (MOR) and modulus of elasticity (MOE), and in the cone calorimeter to evaluate mass loss and heat release rate.

\section{Materials and Methods}

\subsection{Wood Based Panels Artificial Aging}

The wood panels were aged artificially using a cycle of humidity and temperature for indoor environments. Although ETAG 028:2012, [9], is specifically applied to construction products protected by paints, varnishes and surface-impregnated products, and for products with FR treatments applied on construction sites, it was used as a reference for the definition of the aging cycle, depending on the product category of use. The categories of use are referred as type $\mathrm{X}$, used in internal and external applications and exposed to rain and ultraviolet radiation, type $\mathrm{Y}$, intended for indoor and outdoor environments not exposed to rain or UV, Z1 used in indoor environments exposed to high humidity and Z2 used for internal use only.

The cycle used in this paper reproduces the category of use of type Z1, similar to DRF class INT 2 in EN 16755, in which the panels are exposed to $27 \pm 2{ }^{\circ} \mathrm{C}$ and $90 \pm 5 \%$ relative humidity during $8 \mathrm{~h}$, following of $16 \mathrm{~h}$ at $23 \pm 2{ }^{\circ} \mathrm{C}$ and $50 \pm 3 \%$ relative humidity, resulting in a 24-hour cycle, carried out for 10 days without interruption for an expected life of 5 years, [10]. Figure 1 shows the experimental sequence for the mechanical characterization and reaction to fire analysis of aged and non-aged wood based samples. 


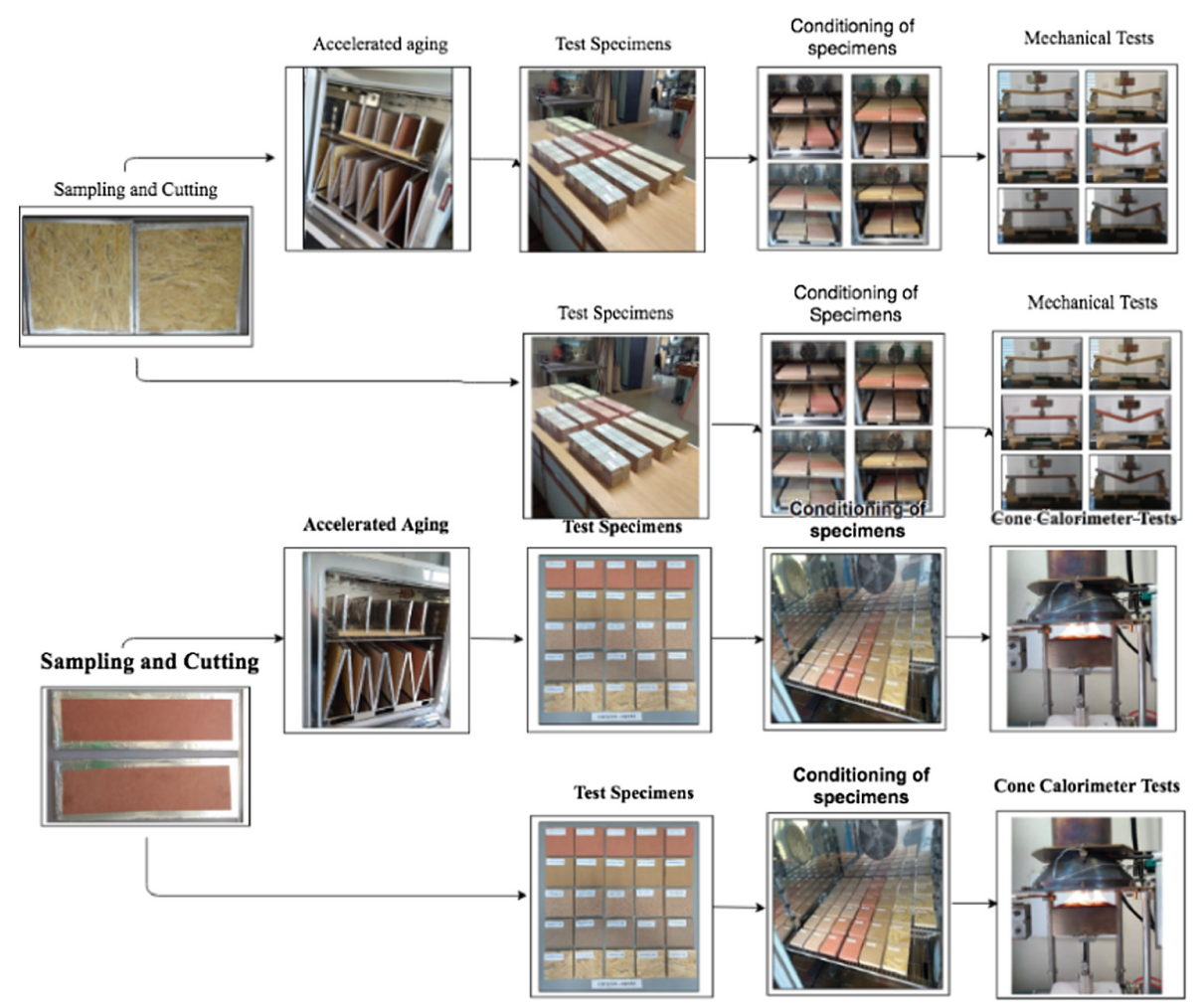

Fig. 1. Sequential procedure used for mechanical and reaction to fire tests.

\subsection{Mechanical Characterization}

The mechanical characterization was done in five different wood based panels, with and without fire retardant: standard Medium Density Fiberboard without fire retardant (MDF-ST-NFR), Medium Density Fiberboard with fire retardant (MDF-FR), Particle Board type P2 without fire retardant (PB-P2-NFR), Particle Board type P2 with fire retardant (PB-P2-FR) and Oriented Strand Board type 4 without fire retardant (OSB3NFR). The panels were all supplied by the company Sonae Arauco, [17]. The FR components are mixed and added to de resin during the panels production process. The type of resin used in the production varies. The UF/MUF, Urea-Formaldehyde and Melamine-Urea-Formaldehyde, resin is used in MDF and PB panels, while pMDI, polymeric diphenyl methane diisocyanate, resin is used in the OSB production.

The mechanical properties of the panels provided by the manufacturer and its fire reaction classes are shown in Table 3.

The mechanical strength was determined by the standard EN310 [16], using the three-point bending test to determine bending strength (MOR) and Modulus of elasticity (MOE). 
There were a total of 20 tested specimens for each MDF, PB and OSB panel, following the cutting plan of EN310. Each panel cut in two groups of ten specimens, for each orientation $0^{\circ}$ and $90^{\circ}$, with half of the samples tested with the upper side on the top and other half with the lower side on the top.

Table 3. Mechanical properties of the manufacturer.

\begin{tabular}{|c|c|c|c|c|c|c|}
\hline \multirow[t]{2}{*}{ Ref. panel } & \multirow[t]{2}{*}{$\begin{array}{l}\text { Thickness ranges } \\
{[\mathrm{mm}]}\end{array}$} & \multirow[t]{2}{*}{$\begin{array}{l}\text { Class of Reaction to } \\
\text { fire }\end{array}$} & \multicolumn{2}{|c|}{$\begin{array}{l}\text { Bending } \\
\text { strength } \\
{[\mathrm{MPa}]}\end{array}$} & \multicolumn{2}{|c|}{$\begin{array}{l}\text { Modulus of } \\
\text { Elasticity } \\
{[\mathrm{MPa}]}\end{array}$} \\
\hline & & & $0^{\circ}$ & $90^{\circ}$ & $0^{\circ}$ & $90^{\circ}$ \\
\hline MDF-FR & $13-19$ & B-s2, d0 & 20 & - & 2200 & - \\
\hline $\begin{array}{l}\text { MDF-ST- } \\
\text { NFR }\end{array}$ & $13-19$ & D-s2, d0 & 20 & - & 2200 & - \\
\hline PB-P2-FR & $14-20$ & B-s1, d0 & 11 & - & 1600 & - \\
\hline PB-P2-NFR & $14-20$ & D-s2, d0 & 11 & - & 1600 & - \\
\hline OSB3-NFR & $18-25$ & $\mathrm{D}-\mathrm{s} 2, \mathrm{~d} 0$ & 26 & 14 & 4800 & 1900 \\
\hline
\end{tabular}

The test specimens were rectangular with length between supports based on the panel thickness. Since the width is $\mathrm{b}(50 \pm 1) \mathrm{mm}$ and the length between the supports is 20 times the nominal thickness ( $\mathrm{t}$ ), the total length is $11 \mathrm{~mm}$ (length between the supports), plus $50 \mathrm{~mm}$. Table 4 represents the specimens size for each panel type used in the tests.

Table 4. Dimensions of test pieces used in the test.

\begin{tabular}{l|l|l|l|l|l}
\hline Types of panels & $\begin{array}{l}\mathrm{N}^{\mathrm{o}} \text { of } \\
\text { test } \\
\text { pieces }\end{array}$ & $\begin{array}{l}\text { Width } \\
\text { (b) }[\mathrm{mm}]\end{array}$ & $\begin{array}{l}\text { Thickness } \\
\text { (t) }[\mathrm{mm}]\end{array}$ & $\begin{array}{l}\text { Length between } \\
\text { the supports }(11) \\
{[\mathrm{mm}]}\end{array}$ & $\begin{array}{l}\text { Total } \\
\text { length (12) } \\
{[\mathrm{mm}]}\end{array}$ \\
\hline MDF-FR-0 $^{\circ}$ & 10 & 50 & 16 & 320 & 370 \\
\hline MDF-FR-90 $^{\circ}$ & 10 & 50 & 16 & 320 & 370 \\
\hline MDF-NFR-0 $^{\circ}$ & 10 & 50 & 16 & 320 & 370 \\
\hline MDF-NFR-90 $^{\circ}$ & 10 & 50 & 16 & 320 & 370 \\
\hline PB-FR-0 $^{\circ}$ & 10 & 50 & 15 & 300 & 350 \\
\hline PB-FR-90 & 10 & 50 & 15 & 300 & 350 \\
\hline PB-NFR-0 & 10 & 50 & 15 & 300 & 350 \\
\hline PB-NFR-90 $^{\circ}$ & 10 & 50 & 15 & 300 & 410 \\
\hline OSB3-NFR-0 $^{\circ}$ & 10 & 50 & 18 & 360 & 410 \\
\hline OSB3-NFR-90 $^{\circ}$ & 10 & 50 & 18 & 360 & \\
\hline & & & & & 350 \\
\hline
\end{tabular}

The test specimens were conditioned in a climatic chamber (ACS DM600) to a constant mass, for all the samples to enter in a hygroscopic equilibrium in an atmosphere with relative humidity of $(65 \pm 5) \%$ and a temperature of $(20 \pm 2){ }^{\circ} \mathrm{C}$, 
according to Fig. 2. Conditioning of test specimens. It was considered that a constant mass was reached when the results of two consecutive measurements of the test piece mass, carried out at $24 \mathrm{~h}$ of distance, are not differing of more than $0,1 \%$, which means that the test piece mass cannot differ more than $0.10 \mathrm{~g}$. Eight days of conditioning were necessary so that the constant mass be reached.

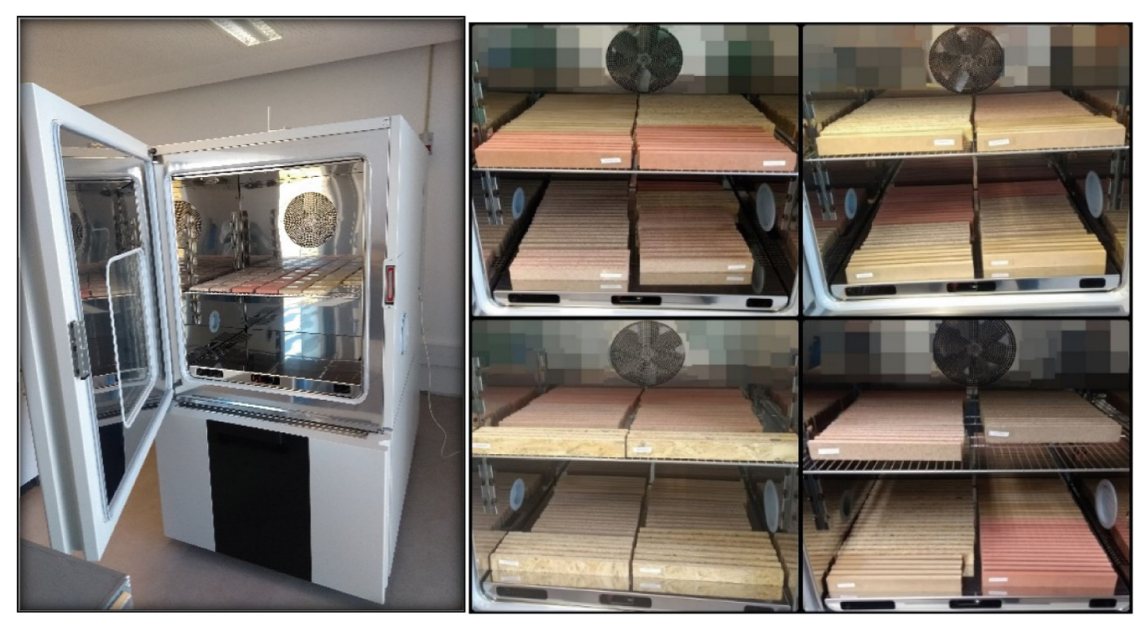

Fig. 2. Conditioning of test specimens.

The three point bending test was done using an Universal testing machine suitable for bending tests up to 100 [kN], INSTRON 3382. The setup consists of a cylindrical load head with $30[\mathrm{~mm}]$ diameter placed parallel to the supports at the specimen mid span, as in Fig. 3. The supports are adjustable to allow the different length specimens support on a cylindrical clamp with 15 [mm] diameter, as shown in Fig. 3.

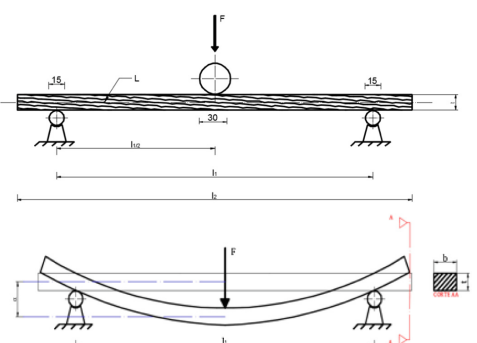

Fig. 3. Schematic representation of the test and measurement of deflection, [16].

The load was applied at a rate determined to achieve the maximum load within $60 \pm 30 \mathrm{~s}$ throughout the test. The mid span vertical displacement was also measured during the tests. 
The bending strength calculation (MOR) was calculated from the following Eq. 1.

$$
\mathrm{MOR}=\frac{3 \mathrm{~F}_{\text {máx }} \mathrm{l}_{1}}{2 \mathrm{bt}^{2}}
$$

Where $F_{\text {máx }}$ represents the maximum load $(\mathrm{N}), l_{1}$ is the distance between the centers of the two supports (mm), $t$ is the thickness of the test specimens (mm) and $b$ is the width of the test specimens.

For the modulus of elasticity (MOE) calculation, it was necessary to use Eq. 2, having a direct relationship between MOE and the maximum strength obtained in the bending test. The way in which the MOE should be calculated in the sample elastic regime, as proposed by the EN 310 standard [16], uses $F_{1}$ corresponding to $10 \%$ of the max break strength and $F_{2}$ corresponding to $40 \%$ of the $\alpha_{1}$ and $\alpha_{2}$ deformations.

$$
\operatorname{MOE}=\left[\frac{l_{1}^{3}\left(F_{2}-F_{1}\right)}{4 b t^{3}\left(\alpha_{2}-\alpha_{1}\right)}\right]
$$

\subsection{Reaction to Fire Performance of Wood Based Panels}

For the evaluation of the reaction to fire, a mass loss calorimeter was used according to ISO 5660, [13], see Fig. 4b. The samples were exposed in horizontal orientation to a radiant heat flux of $50\left[\mathrm{~kW} / \mathrm{m}^{2}\right]$ positioned at a distance of $25[\mathrm{~mm}]$ from the cone base. An ignitor was positioned above the test sample since the beginning of the test and removed when the material ignition started. During the tests, the following parameters were obtained: heat release rate (HRR), ignition time (IT), total heat release (THR) and residual mass $(\mathrm{m} / \mathrm{m} 0)$. The dimensions used were $100[\mathrm{~mm}] \times 100[\mathrm{~mm}] \times$ thickness, indicated in Table 5. This table also shows the number of tests used with and without accelerated aging, referenced as AGED and NAGED, respectively, and the fire reaction class obtained from the product data sheet.

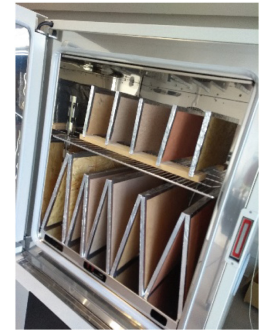

(a)

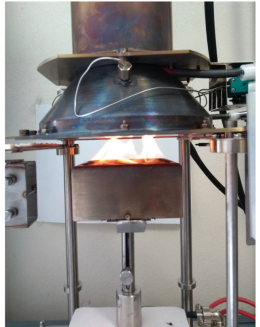

(b)

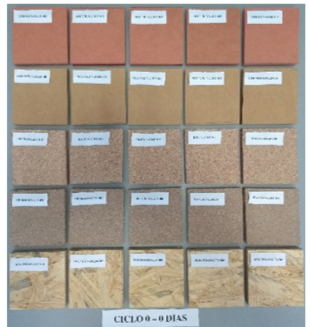

(c)

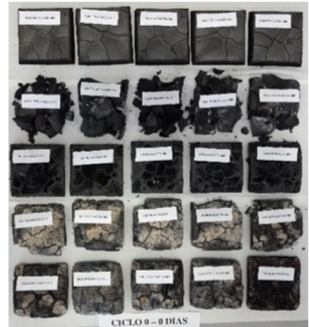

(d)

Fig. 4. (a) Samples at the climate chamber. (b) Cone calorimeter test. (c) Samples before fire reaction test. (d) Samples after fire reaction test. 
Table 5. Number of specimens tested in the cone calorimeter.

\begin{tabular}{l|l|l|l|l}
\hline Panel type & \multirow{2}{*}{ Fire reaction class } & \multicolumn{2}{l|}{$\mathrm{N}^{\circ}$ of samples } & \multirow{2}{*}{ Thickness [mm] } \\
\cline { 3 - 5 } & & NAGED & AGED & \\
\hline MDF-FR & B-s2, d0 & 4 & 4 & 16 \\
\hline MDF-ST-NFR & D-s2, d0 & 4 & 5 & 16 \\
\hline PB-P2-FR & B-s1, d0 & 4 & 5 & 15 \\
\hline PB-P2-NFR & D-s2, d0 & 5 & 4 & 15 \\
\hline OSB3-NFR & D-s2, d0 & 4 & 5 & 18 \\
\hline
\end{tabular}

Before the tests, the samples were also submitted to the atmospheric conditioning to reach the hygroscopic equilibrium at temperature of $(23 \pm 2)\left[{ }^{\circ} \mathrm{C}\right]$ and relative humidity $(\mathrm{RH})$ of $(50 \pm 5)[\%]$.

The results of the heat release rate and the total heat released measured by the tests carried out in the calorimeter allows to evaluate the durability, through the accelerated aging cycles, on the fire reaction of the samples, and thus to reclassify the fire reaction of the samples. This performance is analyzed with reference to EN 16755 [12], which considers the criteria presented in Table 6 for the definition of the reaction to fire after climatic exposure.

Table 6. DRF classification criteria for small scale fire testing after weather exposure, [12].

\begin{tabular}{l|l}
\hline & Building products excluding floorings \\
\hline Heat flux & $50 \mathrm{~kW} / \mathrm{m}^{2}$ \\
\hline $\begin{array}{l}\text { Criteria for small scale fire testing } \\
\text { after weather exposure }\end{array}$ & Class B products (according to EN 13501-1): Heat \\
& $\begin{array}{l}\text { Release Rate, HRR30s ave } \leq 150 \mathrm{~kW} / \mathrm{m}^{2} \text { during } 600 \mathrm{~s} \\
\text { after ignition and Total Heat Release THR600s } \\
\text { increase }<20 \% \text { compared to fire testing before the } \\
\text { weather exposure } \\
\text { Class C products (according to EN 13501-1): HRR 30s } \\
\text { ave } \leq 220 \mathrm{~kW} / \mathrm{m}^{2} \text { during } 600 \mathrm{~s} \text { after ignition and } \\
\text { THR600s increase }<20 \% \text { compared to fire testing before } \\
\text { the weather exposure }\end{array}$ \\
\hline
\end{tabular}

\section{Results and Discussions}

The most distinctive property of the MDF panels is its homogeneous composition, due to their reduced particles size. Thus, the mechanical properties between the test specimens do not vary much, regardless the orientation of the panel cut. An MDF panel feature is that outer layers have a higher density compared to inner layers, it follows that the outer layers have a higher compaction, occasionally causing greater mechanical resistance compared to other panel types, [18].

The experimental results from the MDF wood based panels are shown in the Figs. 5 and 6 for the fire retardant and non-fire retardant panels, respectively. 
Considering the non-aged samples, the average values for the $0^{\circ}$ orientation test specimens were of $30.21[\mathrm{MPa}]$ for MOR and 3.18 [GPa] for the MOE. For the $90^{\circ}$ orientation those values are of $29.53[\mathrm{MPa}]$ and 3.21 [GPa]. For panels without fire retardant the mean values of MOR and MOE were $32.83[\mathrm{MPa}$ ] and $3.13[\mathrm{GPa}$ ] for the test specimens at $0^{\circ}$, and for the values at $90^{\circ}$ the MOR and MOE was 31.87 and 3.12 [GPa].

Comparing the results from non-aged and aged tests, can be verified a reduction of MOR and MOE in both MDF board types with aging. The highest perceptual reduction is always for the $90^{\circ}$ test results in both mechanical properties. Equally an higher reduction of both properties is obtained with aging for MDF-NFR panel, in comparison to the fire retardant panel (MDF-NFR).

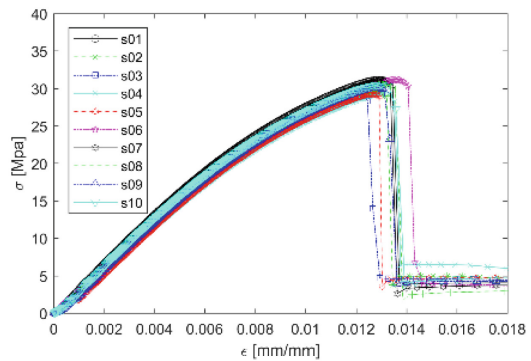

(a)

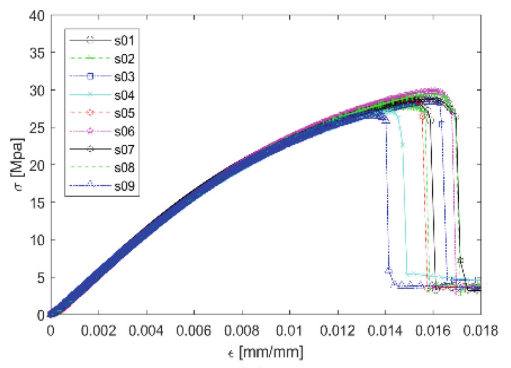

(c)

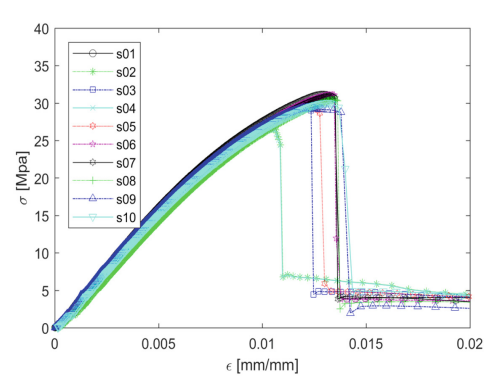

(b)

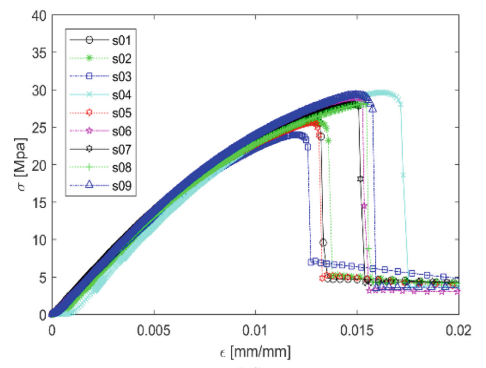

(d)

Fig. 5. Bending strength MDF-FR: (a) Direction $0^{\circ}$ NAGED, (b) Direction $90^{\circ}$ NAGED, (c) Direction $0^{\circ}$ AGED, (d) Direction $90^{\circ}$ AGED.

The particleboard panels have the most consistent values among those provided, due to the reduced size of its particles and high degree of homogeneity. The test results are represented in the next figures (Figs. 7 and 8).

There was apparently no significant variation of MOR and MOE in both directions, but fire-retardant panels had a higher modulus of elasticity and a small variation compared to MOR values. The mean values of MOR and MOE for PB-P2-FR were of $11.10[\mathrm{MPa}]$ and $2.54[\mathrm{GPa}]$ respectively for the $0^{\circ}$ direction. The mean values for the specimens tested at $90^{\circ}$ were of $11.85[\mathrm{MPa}]$ and 2.73 [GPa] respectively. 


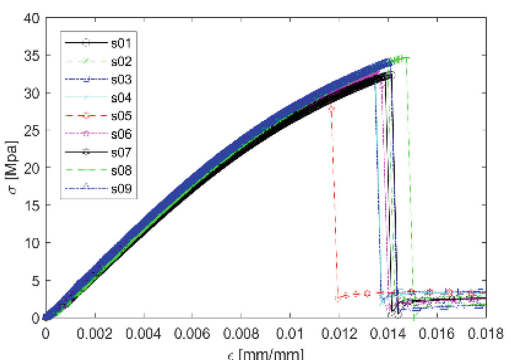

(a)

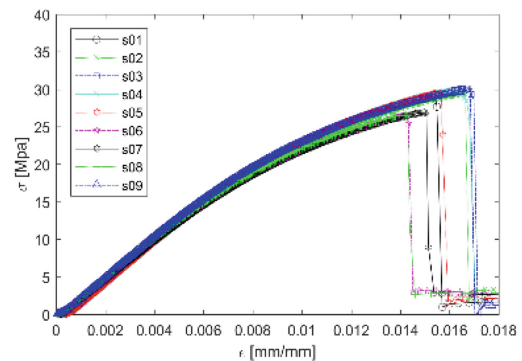

(c)

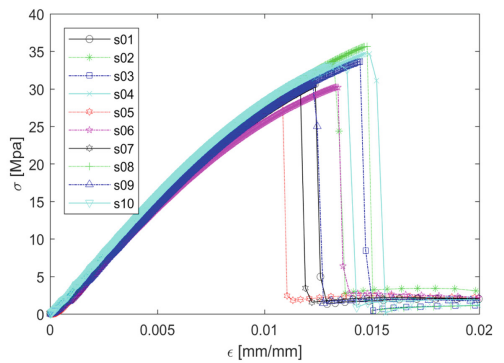

(b)

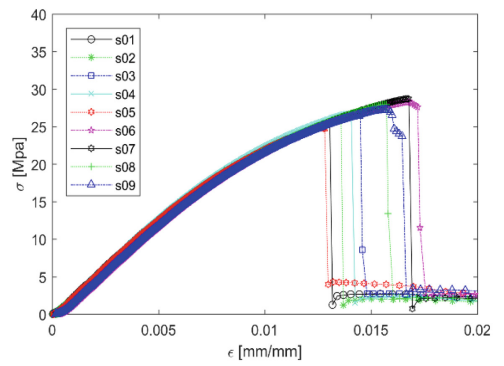

(d)

Fig. 6. Bending strength MDF-ST-NFR: (a) Direction $0^{\circ}$ NAGED, (b) Direction $90^{\circ}$ NAGED, (c) Direction $0^{\circ}$ AGED, (d) Direction $90^{\circ}$ AGED.

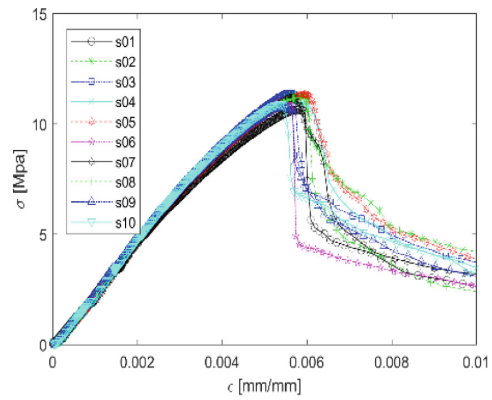

(a)

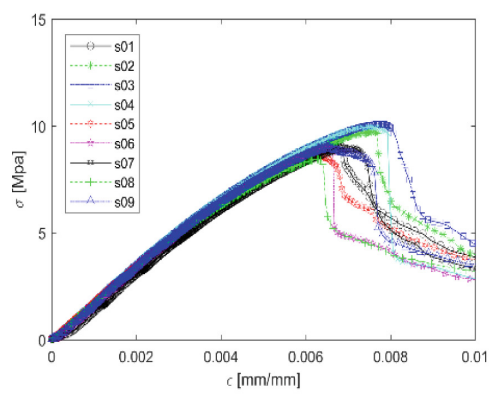

(c)

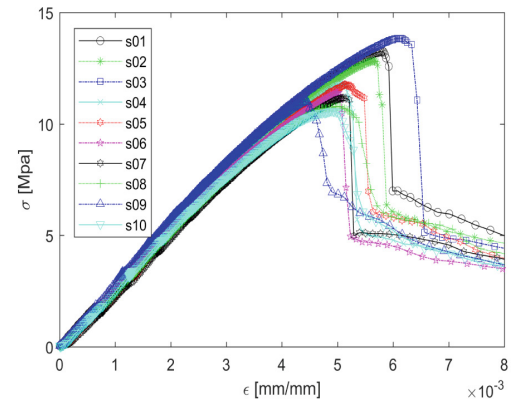

(b)

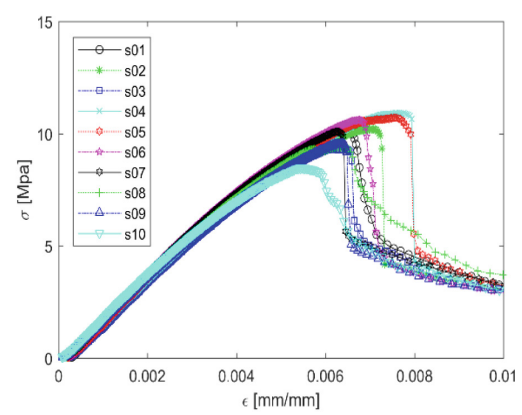

(d)

Fig. 7. Bending strength PB-P2-FR: (a) Direction $0^{\circ}$ NAGED, (b) Direction $90^{\circ}$ NAGED, (c) Direction $0^{\circ}$ AGED, (d) Direction $90^{\circ}$ AGED. 
For the PB-P2-NFR panels, the mean values were of $11.59[\mathrm{MPa}]$ and $2.31[\mathrm{GPa}]$ at $0^{\circ}$ for the MOR and MOE values, respectively, and for the $90^{\circ}$ tests, were of 11.52 [MPa] and 2.35 [GPa].

The mechanical properties deterioration with the accelerated aging was more significate for this type of panels. In the case of PB-P2-FR the reduction was $16.84 \%$ for MOR and $31.38 \%$ for MOE at $0^{\circ}$ direction, and for the $90^{\circ}$ direction a reduction of $16.01 \%$ and $26.41 \%$ was obtained for MOR and MOE, respectively.

For the standard particleboard panel, PB-P2-NFR, a similar reduction magnitude was obtained after aging the samples, being the highest reduction also for the $0^{\circ}$ direction tests.

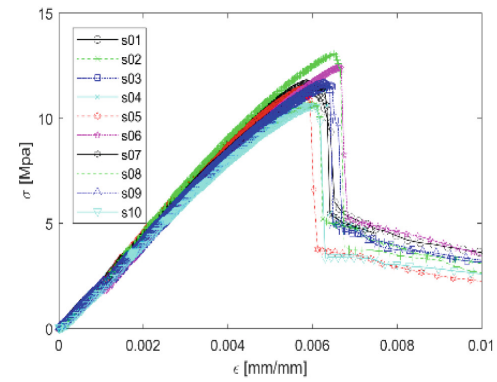

(a)

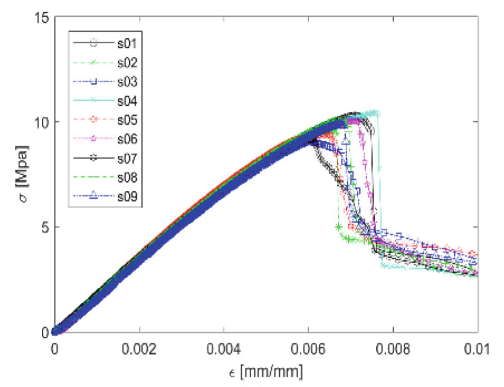

(c)

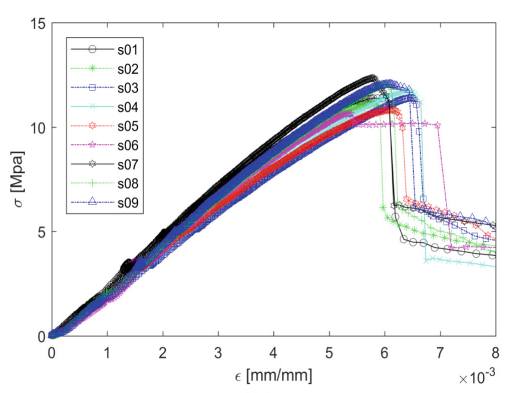

(b)

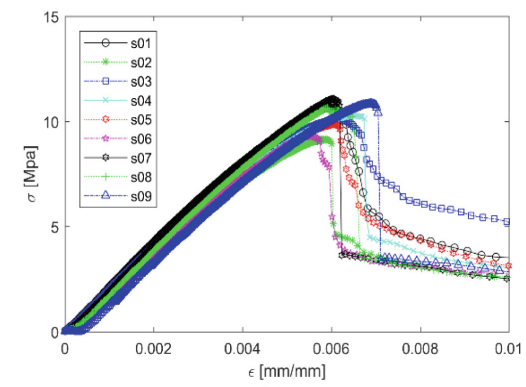

(d)

Fig. 8. Bending strength PB-P2-NFR: (a) Direction $0^{\circ}$ NAGED, (b) Direction $90^{\circ}$ NAGED, (c) Direction $0^{\circ}$ AGED, (d) Direction $90^{\circ}$ AGED.

The OSB panels presented more dissimilar flexural strength values between the specimens. This behavior is due to the lack of a uniform panel density inside the plate, this implies that specimens have a higher surface density, and consequently, higher values of static bending [19]. However, the higher density in the lower part of the board implies smaller values of bending strength, as shown in Fig. 9.

The behavior of the OSB panels has shown a remarkable difference between the two orientations. This difference is so significant because the wood fibres in the parallel orientation are better organized and oriented to counter the pressure and therefore resist to higher values of tension. 


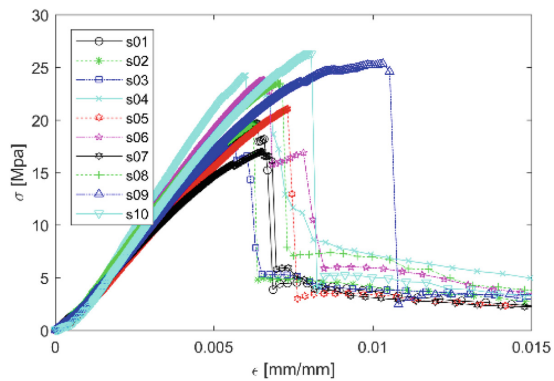

(a)

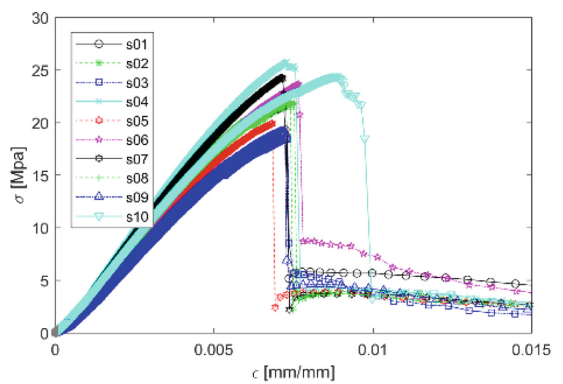

(c)

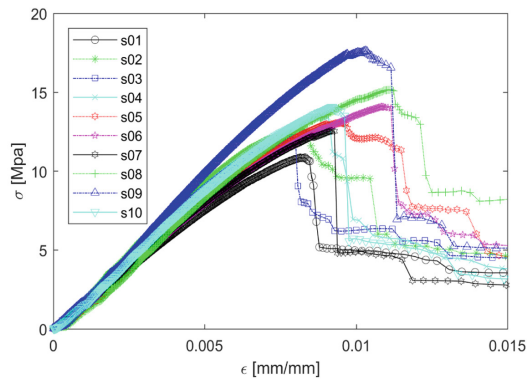

(b)

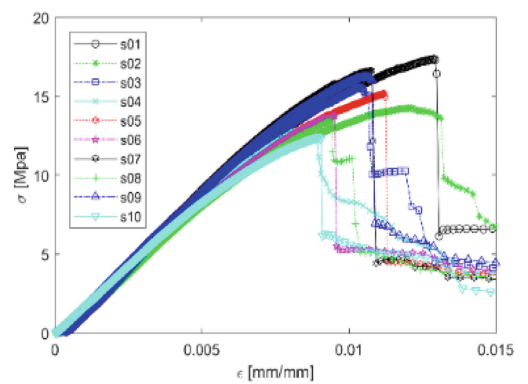

(d)

Fig. 9. Bending strength OSB-NFR: (a) Direction $0^{\circ}$ NAGED, (b) Direction $90^{\circ}$ NAGED, (c) Direction $0^{\circ}$ AGED, (d) Direction $90^{\circ}$ AGED.

A significant difference was observed in the test specimens values having the same orientation. The average value found for the panels tested at an orientation of $0^{\circ}$ was $21.80[\mathrm{MPa}]$ for MOR and 3.93 [GPa] for MOE. In the panels tested at $90^{\circ}$ the values of the analyzed mechanical properties are significantly reduced, resulting in MOR and MOE values of $13.56[\mathrm{MPa}]$ and $1.88[\mathrm{GPa}]$, respectively.

OSB panel samples present the smallest variation with the aging effect. In fact considering the arithmetic average of all samples, the MOR had a small increase in both directions, while the highest MOE reduction was obtained at $0^{\circ}$ direction, with a value of $5.75 \%$. Considering the test dispersion of results, verified by the MOR standard deviation values, no definitive conclusion can be obtained about the aging effect on the OSB panels. A further experimental work is needed.

The complete experimental three point bending test results performed to all wood based panels are presented in Table 7. The table shows the average values of the Bending strength (MOR) and the Modulus of elasticity (MOE) for both directions $\left(0^{\circ}\right.$ and $90^{\circ}$ ) of all samples before and after the accelerated aging. 
Table 7. Three Point bending test results.

\begin{tabular}{l|l|l|l|l|l|l|l|l|l}
\hline Wood based panel & \multicolumn{3}{|l|}{$\begin{array}{l}\text { Bending strength } \\
\text { (MOR) [MPa] }\end{array}$} & \multicolumn{4}{l}{$\begin{array}{l}\text { Modulus of elasticity } \\
\text { (MOE) [GPa] }\end{array}$} \\
\cline { 2 - 10 } & NAGED & \multicolumn{2}{|l}{ AGED } & \multicolumn{2}{l}{ NAGED } & \multicolumn{2}{|l}{ AGED } \\
\cline { 2 - 10 } & $0^{\circ}$ & $90^{\circ}$ & $0^{\circ}$ & $90^{\circ}$ & $0^{\circ}$ & $90^{\circ}$ & $0^{\circ}$ & $90^{\circ}$ \\
\hline MDF-NFR & 32,83 & 31,87 & 28,61 & 26,87 & 3,13 & 3,12 & 2,67 & 2,60 \\
\hline MDF-FR & 30,21 & 29,53 & 28,35 & 27,32 & 3,18 & 3,21 & 2,82 & 2,81 \\
\hline PB-P2-NFR & 11,59 & 11,52 & 9,77 & 10,21 & 2,31 & 2,35 & 1,81 & 2,07 \\
\hline PB-P2-FR & 11,10 & 11,85 & 9,23 & 9,95 & 2,54 & 2,73 & 1,75 & 2,01 \\
\hline OSB3-NFR & 21,80 & 13,56 & 22,09 & 14,76 & 3,93 & 1,88 & 3,71 & 1,83 \\
\hline
\end{tabular}

Figure 10 shows the heat release rate variation from particleboard panels, with a moving average of $30 \mathrm{~s}$ (HRR_30s), before and after the aging cycle. During the tests there was no significant difference in the residual mass of the samples, so their variation is not shown here. The average values of all the samples tested are shown in Table 7 for the different types of panels.

The aging cycle applied to the PB-NFR panels significantly influenced the total heat released (THR) up to $600 \mathrm{~s}$ of exposure, resulting in average values of 45.71 $\left[\mathrm{MJ} / \mathrm{m}^{2}\right]$ for aged panels and $63.36\left[\mathrm{MJ} / \mathrm{m}^{2}\right]$ for the non-aged. There was a decrease in THR between non aged and aged panels of $27.8 \%$ and $16.5 \%$ for products without flame retardant and flame retardant, respectively.

Exposure to temperature and humidity cycles causes changes in the behavior of urea-formaldehyde resin by releasing volatile compounds, reducing their contribution to the combustion of the panel. The ignition time of PB-NFR-NAGED was 32.2 [s] and the PB-NFR-AGED was 41.75 [s].

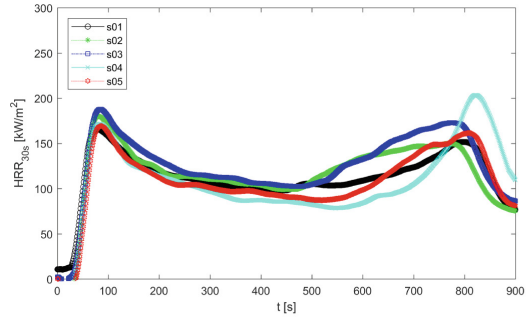

(a)

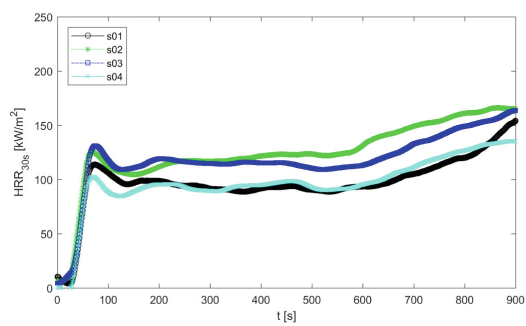

(c)

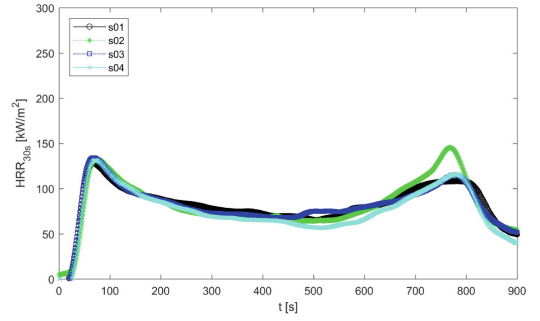

(b)

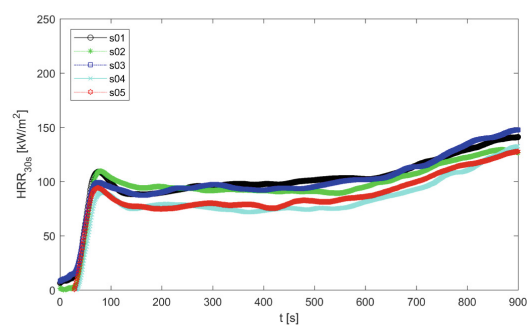

(d)

Fig. 10. HRR results. (a) PB-NFR and NAGED. (b) PB-NFR and AGED. (c) PB-FR and NAGED. (d) PB-FR and AGED. 
With the exception of MDF panels without flame retardant, exposure to accelerated aging leads to a reduction in the rate of heat release as shown in Table 8. In the MDFNFR samples the THR increased from 56.87 to $67.75\left[\mathrm{MJ} / \mathrm{m}^{2}\right]$ after aging, while the ignition time decreases from 38.5 to 33.5 [s] in aged panels. In the case of MDF panels with fire retardant, there was no ignition and THR was lower in aged samples, similar to $\mathrm{PB}$ panels, changing from 11.35 to $11.03\left[\mathrm{MJ} / \mathrm{m}^{2}\right]$.

Table 8. Results and comparison between aged and non-aged wood based panels.

\begin{tabular}{|c|c|c|c|c|c|c|}
\hline \multirow[t]{2}{*}{ Panel type } & \multicolumn{2}{|c|}{$\mathrm{HRR}_{30 \mathrm{~s}}\left[\mathrm{~kW} / \mathrm{m}^{2}\right]$} & \multicolumn{2}{|l|}{$\begin{array}{l}\mathrm{THR}_{600 \mathrm{~s}} \\
{\left[\mathrm{MJ} / \mathrm{m}^{2}\right]}\end{array}$} & \multicolumn{2}{|l|}{ TI [s] } \\
\hline & NAGED & AGED & NAGED & AGED & NAGED & AGED \\
\hline PB-P2-FR & 108.183 & 93.228 & 58.706 & 49.024 & 38.0 & 42.2 \\
\hline PB-P2-NFR & 111.555 & 75.038 & 63.360 & 45.711 & 32.2 & 41.75 \\
\hline MDF-FR & 28.456 & 21.902 & 11.356 & 11.033 & - & - \\
\hline MDF-ST-NFR & 94.094 & 120.916 & 56.875 & 67.754 & 38.5 & 33.5 \\
\hline OSB4-NFR & 184.401 & 122.820 & 103.83 & 65.377 & 32.0 & 29.4 \\
\hline
\end{tabular}

The behavior observed in the OSB-NFR panels was similar to PB-NFR, in which the THR decrease after the aging of the samples, releasing less heat. The ignition time also decreased in relation to the non-aged samples, from 32 to 29.4 [s].

The reaction to fire performance after accelerated aging exposure of wood based panels with fire retardants (PB-P2-FR and MDF-FR), considering the rate of heat release and the total heat released, according to Table 6 , allows to classify them in class $\mathrm{B}$ of reaction to fire after the exposure to accelerated aging.

\section{Conclusions}

Wood based panels is being used in building construction as a construction product. To overcome the lack of fire reaction it is frequent that wood based panel's producers to offer panels with fire retardants. It is not fully known how this panel behave in the long term, or if they are able to maintain their fire reaction classification when exposed to accelerated aging conditions (humidity and temperature variations). The main goal of this study is to give some clarification about the durability of fire reaction performance of wood based panels with and without fire retardants.

This work presented a set of experimental tests to determine mechanical properties of MDF, PB and OSB wood based panels. The Bending strength (MOR) and Modulus of elasticity (MOE) determined agree with the boards manufacture, except for the case of MDF panels where a difference of about $10[\mathrm{MPa}]$ was verified.

Also the MDF panels tests performed at $0^{\circ}$ and $90^{\circ}$ do not showed significant variation, due to panel homogeneity. However the behavior of OSB4 at $0^{\circ}$ and at $90^{\circ}$ is very different, presenting MOR and MOE values about $40 \%$ and $55 \%$ smaller, respectively. 
With the exception of MDF-NFR panels, there was a decrease in the total heat released in the tests performed on the samples after exposure to accelerated aging. The aging of OSB panel without flame retardants resulted in a $37 \%$ decrease in THR compared to the non-aged. Considering the DRF classification criteria for small scale fire testing, specified by EN 16755 and mentioned in Table 6, the durability performance analysis allows to maintain the analyzed flame retardant panels in class B of fire reaction.

Acknowledgments. The authors acknowledge the support given by the company Sonae Arauco for providing the wood based panels.

\section{References}

1. European Commission, A Roadmap for moving to a competitive low carbon economy in 2050. European Commission: Brussels (2011)

2. JOUE, EU Construction Products Regulation (No. 305/2011) E. Parliament, Editor. Official Journal of the European Union (2011)

3. Lee, B.-H., et al.: Evaluating the flammability of wood-based panels and gypsum particleboard using a cone calorimeter. Constr. Build. Mater. 25(7), 3044-3050 (2011)

4. Ramage, M.H., et al.: The wood from the trees: the use of timber in construction. Renew. Sustain. Energy Rev. 68, Part 1, 333-359 (2017)

5. Esteves, B.M., Pereira, H.M.: Wood modification by heat treatment: a review. BioResources 4(1), 370-404 (2009)

6. CEN, EN 13501-1: Fire classification of construction products and building elements: part 1 classification using test data from reaction to fire tests. European Committee for Standardization: Brussels, Belgium, p. 41 (2002)

7. Östman, B., Mikkola, E.: European classes for the reaction to fire performance of wood products. Holz als Roh- und Werkstoff 64(4), 327-337 (2006)

8. Luo, J.: Ignition properties of panels coated with finishing fire-retardant paints under external radiation. Procedia Eng. 135, 123-127 (2016)

9. Harada, T.: Time to ignition, heat release rate and fire endurance time of wood in cone calorimeter test. Fire Mater. 25(4), 161-167 (2001)

10. Daniliuc, A., et al.: New trends in wood coatings and fire retardants: biobased monomers and high performance coatings. European Coatings Journal (2012)

11. CEN, EN1995-1-2 Eurocode 5: Design of timber structures - Part 1-2: General - Structural fire design. European Committee for Standardization: Brussels, Belgium (2004)

12. CEN, EN 16755: Durability of reaction to fire performance - Classes of fire-retardant treated wood products in interior and exterior end use applications. European Committee For Standardization: Brussels (2017)

13. Östman, B., et al.: Durability of fire retardant treated wood products at humid and exterior conditions review of literature. Fire Mater. 25(3), 95-104 (2001)

14. Östman, B.A.L., Tsantaridis, L.D.: Durability of the reaction to fire performance of fireretardant-treated wood products in exterior applications - a 10-year report. Int. Wood Prod. J. 8(2), 94-100 (2017)

15. NORDTEST, NORDTEST NT Fire 054, Durability of reaction to fire - Performance classes of fire-retardant treated wood-based products in interior and exterior end use applications. Nordic Innovation Centre (2006) 
16. CEN, EN310 Determination of modulus of elasticity in bending and of bending strength 1993, European Committee for Standardization

17. SonaeArauco, Construction and furniture products: technical data. www.sonaearauco.com

18. Torquato, L.: Caracterização dos painéis MDF comerciais produzidos no brasil, in Engenharia Florestal, Setor de Ciências Agrárias. Universidade Federal do Paraná (2008)

19. Del Menezzi, C.: Estabilização dimensional por meio do tratamento térmico e seus efeitos sobre as propriedades de painéis de partículas orientadas (OSB). Universidade Federal do Paraná (2013) 